Original Article

\title{
DEVELOPMENT AND VALIDATION OF ANALYTICAL METHOD FOR ESTIMATION OF ARIPIPRAZOLE IN SWAB SAMPLES ON PHARMACEUTICAL MANUFACTURING EQUIPMENT SURFACES FOR CLEANING VALIDATION
}

\author{
SUKHPREET KAUR, INDU BALA, ANJOO KAMBOJ*, UPENDRA K JAIN \\ Chandigarh College of Pharmacy, Landran, Mohali, Punjab (140307) \\ Email: anjookamboj@gmail.com
}

Received: 30 Jun 2016 Revised and Accepted: 31 Mar 2017

\begin{abstract}
Objective: To validate simple analytical method and its application in the determination of residual aripiprazole in production area equipment and to confirm the efficiency of cleaning procedure.
\end{abstract}

Methods: The swab sampling and UV method for residual estimation of aripiprazole in swab samples from equipment surfaces after manufacturing of three consecutive batches of aripiprazole $10 \mathrm{mg}$ uncoated tablets were developed and validated.

Results: The swab sampling method was developed and validated in order to obtain the suitable recovery (>90\%). The swabs were saturated with acetonitrile. The UV method was developed using UV-Vis spectrophotometer at $255 \mathrm{~nm}$. The calibration curve was linear ( $\mathrm{r}^{2}=1.0000$ ) over a concentration range of $1-30 \mu \mathrm{g} / \mathrm{ml}$. The LOD and LOQ were $0.43 \mu \mathrm{g} / \mathrm{ml}$ and $1.32 \mu \mathrm{g} / \mathrm{ml}$, respectively. No interference from swab solution was observed and samples were stable for $24 \mathrm{~h}$. The determined concentration varying from $1.00-5.687 \mu \mathrm{g} / \mathrm{swab}$ was well below the calculated limit of contamination i.e., $24.2 \mu \mathrm{g} / \mathrm{swab}$ or $24.2 \mu \mathrm{g} / 25 \mathrm{~cm}^{2}$.

Conclusion: The results obtained from cleaning procedure confirmed that the proposed procedure was able to remove aripiprazole from equipment surfaces below the value of $10 \mathrm{ppm}$ criteria. So the proposed validated UV method with appropriate swab wipe procedure could be applicable for cleaning validation on residues of aripiprazole.

Keywords: Residual estimation, swab sampling, Cleaning validation, Aripiprazole, UV method

(C) 2017 The Authors. Published by Innovare Academic Sciences Pvt Ltd. This is an open access article under the CC BY license (http://creativecommons.org/licenses/by/4.0/) DOI: http://dx.doi.org/10.22159/ijpps.2017v9i5.13788

\section{INTRODUCTION}

Cleaning validation is defined as providing a high degree of assurance that a cleaning process removes residues of the active pharmaceutical ingredients of the product manufactured in a piece of equipment, the cleaning aids utilized in the cleaning process and the microbial attributes $[1,2]$. All residues are removed to predetermined levels to ensure the quality of the next product manufactured is not compromised by waste from the previous product and the quality of future products using the equipment, to prevent cross-contamination and as a GMP requirement. The U. S. food and drug administration (FDA) have strict regulation about the cleaning validation. For example, FDA requires firms to have written general procedures on how cleaning processes will be validated. Also, FDA expects the general validation procedures to address who is responsible for performing and approving the validation study, the acceptance criteria, and when revalidation will be required. FDA also requires firms to conduct the validation studies in accordance with the protocols and to document the results of studies. The valuation of cleaning validation is also regulated strictly, which usually mainly covers the aspects of equipment design, cleaning process written, analytical methods and sampling. Each of these processes has their related strict rules and requirements. Regarding the establishment of limits, FDA does not intend to set acceptance specifications or methods for determining whether a cleaning process is validated. But some limits that have been mentioned by industry include analytical detection levels such as $10 \mathrm{ppm}$, biological activity levels such as $1 / 1000$ of the normal therapeutic dose and organoleptic levels [3-5].

Sampling sites is based on the difficult clean geometries of the equipment and these locations are inaccessible i.e. their inaccessibility makes them difficult to clean, therefore, before choosing for sampling sites one must be conscious in selecting the desired sampling locations [6]. For validation of cleaning procedure three methods of sampling that are considered to be acceptable, namely direct surface sampling (swab method), indirect sampling (use of rinse solution) and placebo sampling. A combination of the first two methods is generally the most desirable particularly in circumstances where accessibility of equipment parts can mitigate against direct surface sampling $[7,8]$.

The cleaning validation is documented evidence with a high degree of assurance that consistently removes the residue of the subjected product below the established acceptance criteria. For the acceptable residual limit, various mathematical formulas and calculations are done based on known daily dose or on toxicological data along with safety factors. Hence the cleaning validation involves three separate activities: (i) establishment of acceptable residue limits for drug, (ii) development and validation of assay method for determination of drug from equipment surfaces and (iii) the development and validation of cleaning procedure that is used to remove drug from the manufacturing surfaces $[6,9-14,25]$.

Aripiprazole is an atypical antipsychotic drug. It is primarily used in the treatment of psychotic conditions such as schizophrenia and bipolar disorder. It is commercially available as a tablet or as an oral solution. Tablets are available in $10 \mathrm{mg}, 15 \mathrm{mg}, 20 \mathrm{mg}$ and $30 \mathrm{mg}$. Due to low dose profile, it is necessary to prove that the equipment train and production area are clean prior to the development of next product, as per good manufacturing practice.

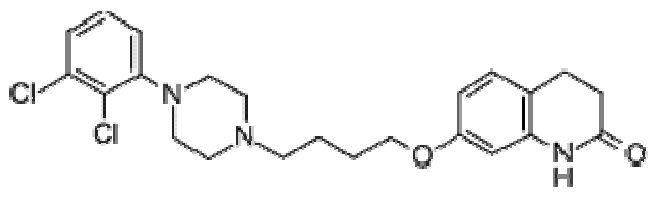

Fig. 1: Aripiprazole [29] 
Aripiprazole $\left(\mathrm{C}_{23} \mathrm{H}_{27} \mathrm{Cl}_{2} \mathrm{~N}_{3} \mathrm{O}_{2}\right)$ m. wt 448.385, 7-\{4-[4-(2, 3-dichlorophenyl)-piperazin-1-yl] butoxy\}-3, 4-dihydroquinolin-2(1H)-one (CAS registry number: 129722-12-9) is white to off-white crystalline powder, freely soluble in acetonitrile, ethanol, methanol, sparingly soluble in water [29].

The objective of this study was to demonstrate the applicability of UV method for estimation of the residues of aripiprazole in cleaning control swab samples from manufacturing surfaces after production of aripiprazole $10 \mathrm{mg}$ uncoated tablets and the efficiency of the cleaning procedure. The analytical method was validated for linearity, accuracy, precision, robustness, ruggedness, LOQ, LOD. The stability of the solutions of aripiprazole was also studied. The studies were carried out as per the established guidelines [15-19, 26 ]. Also, the swabbing procedure was optimised in order to obtain a suitable recovery of the active ingredient. The cleaning validation was performed on three consecutive batches of finished productaripiprazole $10 \mathrm{mg}$ uncoated tablets.

\section{MATERIALS AND METHODS}

\section{Chemicals and reagents}

All the reagents were of analytical grade. Aripiprazole was obtained from Cadila Pharmaceuticals Ltd, Ahmadabad, India. Acetonitrile was obtained from Molychem, Mumbai, India. Swabs were obtained from Himedia Lab. Ltd. Mumbai, India. Stainless steel plates were used in this experimental work. Double distilled water was used throughout the study.

\section{Equipment and instruments}

Single rotary tablet compression machine (Shakti, India), UV Spectrophotometer model 1800 (Shimadzu, Japan).

\section{Establishment of cleaning level acceptance criteria for aripiprazole}

There are several approaches for the establishment of acceptable residual limit (ARL) calculation. ARL is calculated and compared with different approaches and minimum the value of ARL was selected [7, 8].

(i) Calculation of total carryover limit based on therapeutic or medical dose;

(ii) limit of calculation based on $10 \mathrm{ppm}$ criteria (adulteration limit);

(iii) Limit of calculation based on visual inspection.

\section{Calculation of total carryover limits based on therapeutic dosage}

According to this approach, the safety factor is considered as a risk assessment factor. Many companies have chosen to use a standard safety factor of $1 / 1000$ for all limits calculations. This means that any product, when administered at $1 / 1000$ of its daily therapeutic dose (effective dose), will not cause any toxic effect to the patient if administered by the same route.

The basic principle of cleaning validation is that the patient should not take more than $0.1 \%$ of the therapeutic dose (effective dose). The lowest allowable residue level based on pharmacological activity is achieved by using the smallest dosage of the current product and the smallest batch size manufactured using the equipment train. The formula used for the calculation of the lowest allowable residue value is shown:

$$
A R L=\frac{(S T D \times S B S \times S F \times M)}{(M D D \times S S A)}
$$

Where, ARL is the acceptance residual limit, STD is the API smallest therapeutic dose of previous product A ( $\mathrm{mg} /$ unit dose), SBS is the smallest batch size of any subsequent product (mg) to be manufactured in the small equipment train, $\mathrm{SF}$ is the safety factor i.e. $1 / 1000$ or 0.001 , MDD is the maximum daily dose of the product to be manufactured in the same equipment train, $M$ is the surface area/swab $\left(25 \mathrm{~cm}^{2}\right)$, SSA is the shared equipment surface area.

\section{Limit of calculation based on $10 \mathrm{ppm}$ criteria}

It is stated that not more than $10 \mathrm{ppm}$ of the product will appear in the next batch of product. ARL was calculated on the basis of $10 \mathrm{ppm}$ criterion according to below formula.

$$
A R L=\frac{(10 x M B S x M)}{(S S A)}
$$

Where ARL is the acceptance residual limit, MBS is the minimum batch size in kg of any subsequent product to be manufactured in the same equipment train. (Product B), M is the surface area/swab $\left(25 \mathrm{~cm}^{2}\right)$, SSA is the shared equipment surface area.

\section{Limit of calculation on the basis of visual inspection}

Visually equipment surface area must appear clean with no traces of product or any extraneous matter. The VLOD (visually limit of detection) was determined by spiking $5 \times 5 \mathrm{~cm}$ Stainless steel plates with known amount of drug. The lowest level of aripiprazole residue was visually detected.

Development and validation of UV procedure for assay of aripiprazole residues in swab collected from stainless steel plates

\section{Calibration curve of aripiprazole}

A primary stock solution of $1000 \mu \mathrm{g} / \mathrm{ml}$ was prepared in acetonitrile by dissolving $10 \mathrm{mg}$ of aripiprazole in $10 \mathrm{ml}$ acetonitrile. For the preparation of different concentrations, aliquots of stock solution were transferred into series of $10 \mathrm{ml}$ volumetric flasks and volume was made with acetonitrile. Different concentrations were prepared in a range of $1-30 \mu \mathrm{g} / \mathrm{ml}$ of aripiprazole in acetonitrile and absorbance was measured at $255 \mathrm{~nm}$ for standard graph [20].

\section{Validation of developed method as per ICH guidelines}

The developed method for estimation of aripiprazole was validated as per ICH guidelines for validation parameters like accuracy, linearity, limit of detection (LOD), limit of quantification (LOQ), selectivity and robustness and ruggedness $[18,19,28]$.

\section{Linearity}

In order to establish the linearity of the analytical method, a series of dilutions ranging from $1-30 \mu \mathrm{g} / \mathrm{ml}$ were prepared. The absorbance values were noted at $255 \mathrm{~nm}$. Linearity curve was plotted against corresponding concentration values. The compliance with beer's lamberts law (linearity) was found to be in concentration range and noted.

\section{Accuracy}

The accuracy of the method was estimated by determination of recovery for three concentrations (corresponding to 80,100 and $120 \%$ of test solution concentration) covering the range of the method. For each concentration, three sets were prepared and absorbances were noted. The drug concentrations of aripiprazole were then calculated

\section{Recovery study of drug from spiked stainless steel plates}

Recovery study was prepared on spiked stainless steel plates [2023] with a predefined $10 \mathrm{~cm}^{2}$ surface area. $5 \mathrm{ml}$ volume of different concentrations of $1,5,10,15$ and $20 \mu \mathrm{g} / \mathrm{ml}$ of aripiprazole was spiked onto stainless steel plates with five sets of the concentration of five plates each and was allowed to evaporate. The head of adsorbent swabs was saturated with acetonitrile. The total surface of the plates was successively wiped initially in a horizontal and then in a vertical fashion, starting from the outside towards the centre, with swabs moistened with the appropriate solvent. The head of the swabs was placed into a $10 \mathrm{ml}$ volumetric flask containing $5 \mathrm{ml}$ of the solvent (in which the swab was soaked). Then $5 \mathrm{ml}$ of water was added to each volumetric flask. These volumetric flasks were capped and sonicated for $15 \mathrm{~min}$. The absorbance of the solution was measured with UV-Vis spectrophotometer. The UV maxima in acetonitrile were found to be $255 \mathrm{~nm}$.

Precision: Precision was considered at two levels:

\section{Repeatability (Intra-day repeatability)}

The intra-day repeatability was established by analysis 6 different concentrations with three replicates. In intra-day precision, all the replicate was prepared on the same day and 
statistical validation was carried out. The data is represented as relative standard deviation (\% RSD) and with low relative standard deviation (\% RSD) values which indicate the good method precision.

\section{Inter-day precision}

Day to day precision was carried out by analysis 6 concentration with three replicates. In inter-day precision, all the linearity concentrations were prepared and absorbance was recorded. The low relative standard deviation (\% RSD is $\pm 2 \%$ ) values which indicate the good method precision.

\section{Robustness and ruggedness}

Robustness and ruggedness were carried out to evaluate the influence of small but deliberate variations in the experimental conditions for the determination of aripiprazole. Robustness of the method was determined by changing the temperature and ruggedness of the method was determined by changing analyst.

\section{LOD and LOQ}

LOD and LOQ of the method were established using the following formulas as per ICH guideline:

$$
\begin{aligned}
& L O D=\frac{3.3 \sigma}{S} \\
& L O Q=\frac{10 \sigma}{S}
\end{aligned}
$$

Where, $\sigma$ is the mean standard deviation of y-intercepts of regression lines, $\mathrm{S}$ is the slope of the standard curve.

Optimization and validation of cleaning procedure for aripiprazole tablets on compression machine

The cleaning validation was done to demonstrate the effectiveness of the cleaning procedure for residues up to the predetermined acceptance level of aripiprazole in the equipment train [24].

\section{Sampling procedure}

To determine the residue of drug remaining in the equipment train after cleaning swab sampling procedure was used. For this procedure, sterile cotton swabs with polypropylene stick in HDPF bottle were used. Before collecting the samples the swabs were dipped in the acetonitrile and completely saturated for $15 \mathrm{~min}$. For all sampling locations, $5 \mathrm{~cm} \times 5 \mathrm{~cm}$ swab area was selected and swabbed in described swabbing pattern. The pattern of swabbing and pressure applied was such that it collected the maximum residue present in the selected area. All this operation was done with care and wearing powder free sterile gloves in hands. The swab wiped from selected area was placed in the sterile HDPF containing $5 \mathrm{ml}$ of acetonitrile and capped securely. Each tube was sonicated for $5 \mathrm{~min}$; the extract was collected and analyzed by developed method.

\section{Chemical acceptance criteria}

ARL (acceptable residual limit) used to calculate chemical acceptance criteria

Chemical acceptance criteria $=\frac{(\text { ARLx recovery from SS plate surface })}{100}$

\section{Sampling locations}

It is important to include the swab samples from the most difficult to clean and worse case locations of the equipment, but the sampling locations were selected such that these were representative of all areas of equipment, even easy to clean surfaces.

In the given piece of equipment, 99\% surface was readily accessible, easy to clean and visually friendly category. Only $1 \%$ or less equipment surface was hard to clean and it was assumed that the equipment was equally dirty as the hard to clean surface samples obtained.

Following sampling locations were selected for swab sampling of the residual drug from tablet machine after washing (fig. 2; table 1).

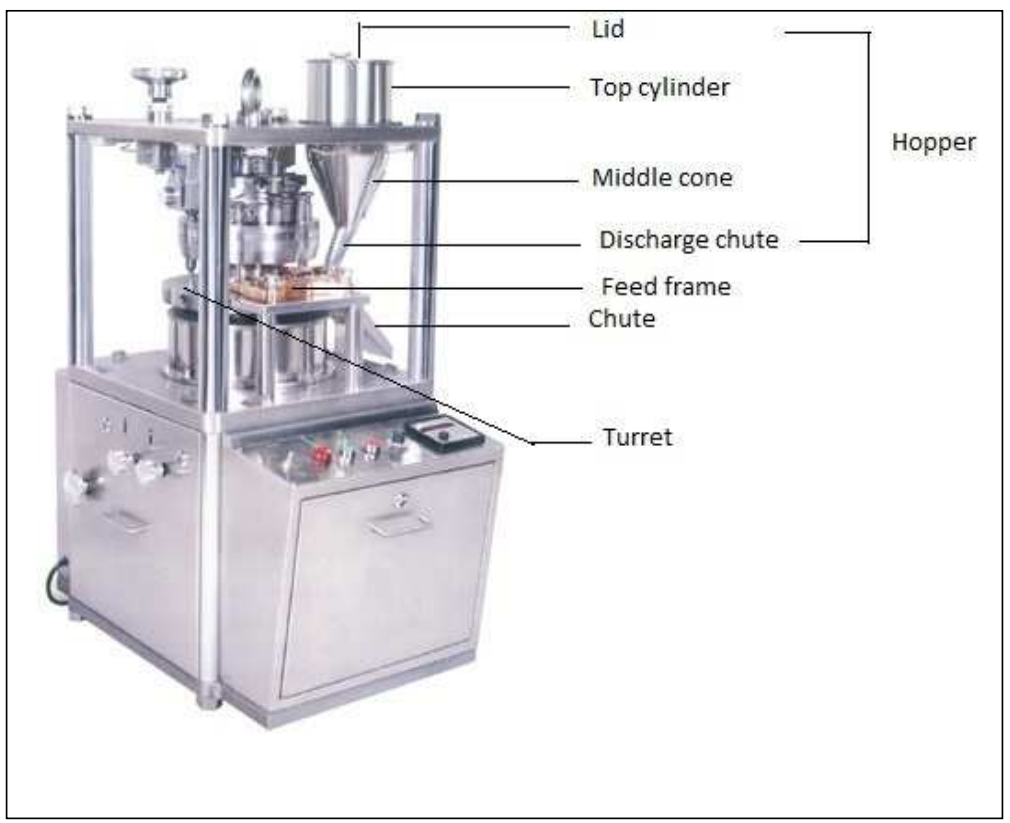

Fig. 2: Different sampling locations in the single rotary tablet compression machine [27]

Table 1: Different sampling locations in the single rotary tablet compression machine [27]

\begin{tabular}{lll}
\hline S. No. & Sampling point location & Sampling point name \\
\hline 1. & Hopper top cylinder & TCM-01 \\
2. & Hopper middle cone & TCM-02 \\
3. & Hopper discharge chute & TCM-03 \\
4. & Turret & TCM-04 \\
5. & Chute & TCM-05 \\
\hline
\end{tabular}




\section{Optimisation of cleaning procedure}

After compression of the tablets of aripiprazole $10 \mathrm{mg}$ the tablet machine was cleaned according to the general procedure used in the industry to clean the pharmaceutical equipment. The samples were collected with cotton swabs by wiping $5 \mathrm{~cm} \times 5 \mathrm{~cm}$ area of predefined sampling locations. Samples were analyzed and compared w. r. $t$ the predetermined acceptance criteria [24].

Following steps were followed in the cleaning procedure of the tablet machine after compression of the aripiprazole $10 \mathrm{mg}$ tablet.

$>$ The main power supply of machine was switched off.

$>$ The pressure was released which was applied on the roller of the machine during compression.

$>$ Previous batch powders, containers and tablets were removed from manufacturing area.

$>$ The loosely stuck powder was wiped from the machine using a dry cloth.

$>$ Compression machine was dissembled as follows:

- Remove the hopper from spindle by unscrewing the upper screws.

- Doors of the machine were opened.

- The feed frame was removed from die table by screwing the upper screws.

- The screws of tablet discharge chute were loosened and removed it from the machine.

○ All above-dissembled parts were subjected to washing.

- Bottom side cover was removed from the machine.

- Upper punches were removed by removing upper punch guide and rotating the turret with the help of flying wheel.

- The die locking screw was unlocked from the turret with allen key and dies were removed with the help of die driving road by pressing through the lower guide hole.

\section{$>$ Cleaning of die and punches}

- The adhered powder was removed from the punches with the help of the dry cloth.

- Punches were cleaned with the help of clean wet dipped in purified water.

- Dies were cleaned by inserting the wet cloth dipped in purified water through the bore. Dies were externally wiped with wet cloth dipped in purified water,

- Cleaned punches and dies were placed into proper cabinet after visual inspection.

- The die lock was cleaned with a clean wet cloth dipped in purified water.

○ Die lock was allowed to air dry after cleaning.

$>$ Cleaning of machine

- The top base of the machine, upper roller, an upper cam track and lower track were cleaned with a wet cloth dipped in purified water followed by cleaning with dry cloth clean.

- All adhered material to turret was removed by means of the vacuum cleaner and then wiped with a clean cloth moistened in water followed by cleaning with a clean cloth soaked with IPA.

- Shank of upper punch, lower punch and die pocket were cleaned with a dry clean cloth.

- Other non-contact parts of the machine were cleaned with a clean dry cloth.

- Doors were cleaned with a cloth moistened with purified water followed by dry clean cloth.

\section{$>$ Washing}

- Hopper, feed frame, liner take off the plate and discharge chute was cleaned by flushing with purified water for not less than $4 \mathrm{~min}$ to remove the adhered materials on SS surfaces.

\section{$>$ Final rinse and drying}

- Finally feed frames, hopper from the inner side, liner takes off the plate and discharge chute was rinsed with purified water not more than 4 min. Excess water was removed with dry clean cloth,

$>$ Cleaned items were carried to machine area.

$>$ The machine was labelled 'Ready to use'.

\section{Validation of cleaning procedures}

For validation of cleaning procedure on tablet machine, three consecutive batches of aripiprazole tablet $10 \mathrm{mg}$ were prepared. This validation was done to prove the effectiveness and consistency of the cleaning procedure. Validation was also done to meet the regulatory requirement of the development method. After production of each batch the tablet compression machine was subjected to above cleaning procedure. Visual and chemically inspection results were recorded.

\section{RESULTS AND DISCUSSION}

Establishment of cleaning level acceptance criteria for aripiprazole

Swab sampling of area hardest to clean was done from equipment used in the manufacturing and residues were found in $\mathrm{mg} / \mathrm{ml}$. the smallest batch sized (SBS) subsequent products were selected for calculating the values of the maximal allowable carryover. ARL was calculated and compared with different approaches and minimum the value of ARL was selected.

\section{Calculation of total carryover limits based on therapeutic dosage}

The formula used for the calculation of the lowest allowable residue value is shown:

$$
A R L=\frac{(S T D \times S B S \times S F \times M)}{(M D D \times S S A)}
$$

Where, ARL is the acceptance residual limit, STD is the smallest therapeutic dose of product A (mg/unit dose), SBS is the smallest batch size of any subsequent product to be manufactured in the small equipment train, SF is the safety factor i.e. $1 / 1000$ or 0.001 , MDD is the maximum daily dose of the product to be manufactured in the same equipment train, $M$ is the surface area/swab $\left(25 \mathrm{~cm}^{2}\right)$, SSA is the shared equipment surface area.

$$
\text { Smallest batch size }=\frac{\text { minimum working capacity in gram }(A)}{\text { Weight of the tablet }}
$$

$A=(1.25 \mathrm{~L}$ (25\% capacity of hopper) $\times 425$ gram/l(average bulk density of subsequent material) $=531.25 \mathrm{gm}$

\section{$B=$ Tablet weight}

SBS (number of dosage unit form $/$ unit batch) $=\frac{531.25}{0.117} \mathrm{gm}$

$=4540.5$ tablets

Shared surface area of the tablet compression machine. Covering hopper, turret, discharge chute was calculated 5,484.64 $\mathrm{cm}^{2}$ (table 2).

$$
\begin{gathered}
A R L=\frac{(S T D \times S B S \times S F \times M)}{(M D D \times S S A)} \\
A R L=\frac{(30 \times 4540.5 \times 0.001 \times 25)}{(10 \times 5484.64)}
\end{gathered}
$$

$=0.0620 \mathrm{mg} / \mathrm{swab}$

$=62 \mu \mathrm{g} / \mathrm{swab}$ or $62 \mu \mathrm{g} / 25 \mathrm{~cm}^{2}$ 
Table 2: Surface area calculation for tablet machine

\begin{tabular}{|c|c|c|c|c|c|c|c|c|}
\hline S. No. & Part name & Geometric shape & $\mathbf{L}$ & $\mathbf{B}$ & $\mathbf{R}$ & $\mathbf{H}$ & Formula used & Surface area in $\mathrm{cm}^{2}$ \\
\hline 1. & Hopper & & & & & & & \\
\hline a. & Top cylinder & Cylinder & & & 23 & 16 & 2Лrh & 2311.04 \\
\hline b. & Middle cone & Double radius cone & & & $\begin{array}{l}\mathrm{r} 1=20.3 \\
\mathrm{r} 2=8.2\end{array}$ & 14 & 2 Л $(\mathrm{r} 1+\mathrm{r} 2) / 2 \times \mathrm{h}$ & 1239.6 \\
\hline c. & Discharge chute & Cylinder & & & 5.1 & 11.5 & 2 Лrh & 368.3 \\
\hline 2. & Turret & Circular & & & $\begin{array}{l}r 1=14 \\
r 2=9\end{array}$ & & Л $(\mathrm{rl})^{2}-Л(\mathrm{r} 2)^{2}$ & 361.1 \\
\hline 3. & & Rectangle & 28 & 15 & & & & 420 \\
\hline 4. & Chute & C channel & 20.5 & 8.8 & & 6 & $\mathrm{Lb}+2 \mathrm{bh}$ & 286 \\
\hline $\begin{array}{l}5 . \\
\text { Total } \\
\text { (+ \% o } \\
\text { Total }\end{array}$ & Lid of hopper & Circular & & & 8 & & $Л r^{2}$ & $\begin{array}{l}200.96 \\
4986.04 \\
498.6 \\
5484.64 \\
\end{array}$ \\
\hline
\end{tabular}

$\mathrm{L}=$ length, $\mathrm{B}=$ breath, $\mathrm{R}=$ radius, $\mathrm{H}=$ height, $\mathrm{J}=3.14$

\section{Limit of calculation based on 10 ppm criteria}

ARL was calculated on the basis of $10 \mathrm{ppm}$ criterion according to below formula.

$$
A R L=\frac{(10 \times M B S \times M)}{(S S A)}
$$

Where ARL is the acceptance residual limit, MBS is the minimum batch size in $\mathrm{kg}$ of any subsequent product to be manufactured in the same equipment train. (Product B), $M$ is the surface area/swab $\left(25 \mathrm{~cm}^{2}\right)$, SSA is the shared equipment surface area.

Minimum batch size $=$ (1.25L (25\% capacity of hopper) x 425 gram/l(average bulk density of subsequent material) $=531.25 \mathrm{gm}$

$=0.531 \mathrm{Kg}$

$$
\begin{aligned}
A R L & =\frac{(10 \times M B S \times M)}{(S S A)} \\
A R L & =\frac{(10 \times 0.531 \times 25)}{(5484.64)}
\end{aligned}
$$

$=0.0242 \mathrm{mg} / \mathrm{swab}$

$=24.2 \mu \mathrm{g} / \mathrm{swab}$ or $24.2 \mu \mathrm{g} / 25 \mathrm{~cm}^{2}$

\section{Limit of calculation on the basis of visual inspection}

The VLOD (visually limit of detection) was determined by spiking $5 \mathrm{x}$ $5 \mathrm{~cm}$ stainless steel plates with known amount of drug concentration $(10-40 \mu \mathrm{g} / \mathrm{ml})$ after evaporation of the sample solution. The lowest level of aripiprazole residues which was visually detected is $40 \mu \mathrm{g} / 25 \mathrm{~cm}^{2}$.

Since ARL value of $24.2 \mu \mathrm{g} / \mathrm{swab}$ was the lowest value out of three values obtained from 3 criterions. Hence $24.2 \mu \mathrm{g} / 25 \mathrm{~cm}^{2}$ was considered as the acceptable residual limit (ARL) for aripiprazole for residual estimation of the determined concentration of aripiprazole residues in swab sample solution should not be more than ARL (acceptance criteria).

Development and validation of UV procedure for assay of aripiprazole residues in swab collected from stainless steel plates

\section{Calibration curve of aripiprazole in acetonitrile}

The stock solution $(1000 \mu \mathrm{g} / \mathrm{ml})$ was prepared in acetonitrile by dissolving $10 \mathrm{mg}$ of aripiprazole in $10 \mathrm{ml}$ acetonitrile. From the stock solution, various dilutions were prepared and absorbance was measured at $255 \mathrm{~nm}$ [22]. The calibration curve was constructed by plotting absorbance vs concentration with linear regression equation $\mathrm{Y}=0.032+0.0006$, regression coefficient $r^{2}$ equal to 1 (fig. 3,4 ). The high value of correlation coefficient indicates good linearity.

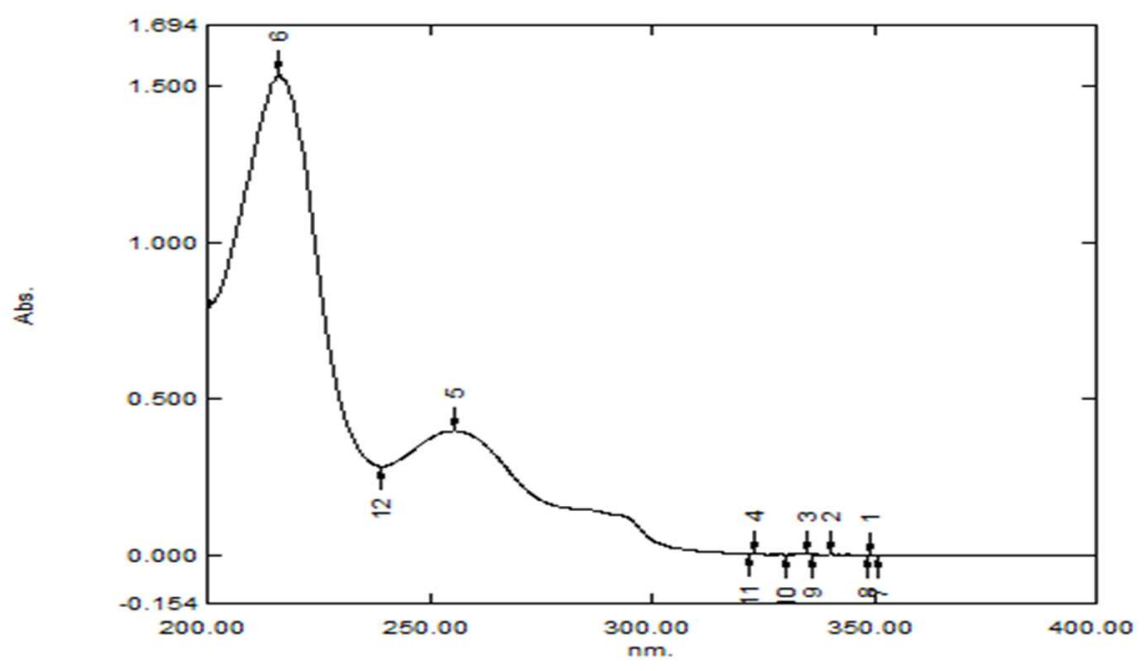

Fig. 3: UV spectrum of aripiprazole in acetonitrile showing absorption maxima at $255 \mathrm{~nm}$ 


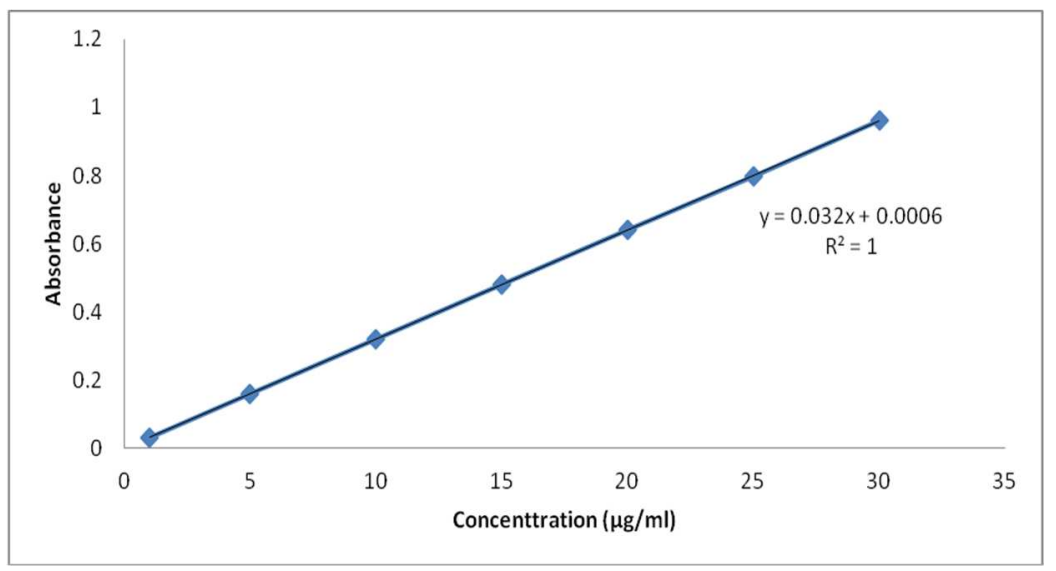

Fig. 4: Calibration curve for aripiprazole

\section{Validation of developed method as per ICH guideline}

\section{Linearity}

Different aliquots were taken from the stock solution and diluted with acetonitrile to prepare series of concentration ranging from 1$30 \mu \mathrm{g} / \mathrm{ml}$. The absorbance value was noted at $255 \mathrm{~nm}$ and plotted against corresponding concentration values. The linearity range was found to be $1-30 \mu \mathrm{g} / \mathrm{ml}$ for aripiprazole. Each measurement was carried out in sextet (table 3 ).

\section{Accuracy}

The accuracy of the method was determined by calculating recovery of aripiprazole by standard addition method. A known amount of standard solution of aripiprazole $(80,100$, and $120 \%)$ added to prequantified separate $(10 \mu \mathrm{g} / \mathrm{ml})$ respectively. The amount of aripiprazole was estimated (table 4).

The low value of standard deviation indicates that the proposed method is accurate. Results of recovery studies are given in table 4 . The \% recovery was found between $95.20 \%-98.82 \%$ which were within the limit of acceptable criteria which indicate indicates that the method has good accuracy for determining aripiprazole [22].

\section{Recovery study of drug from spiked stainless steel plates}

Recovery study was prepared on spiked stainless steel plates with a predefined $10 \mathrm{~cm}^{2}$ surface area. $5 \mathrm{ml}$ volume of different concentrations of $1,5,10,15$ and $20 \mu \mathrm{g} / \mathrm{ml}$ of aripiprazole was spiked onto stainless steel plates with five sets of the concentration of five plates each and was allowed to evaporate. The head of adsorbent swabs was saturated with acetonitrile.

The total surface of the plates was successively wiped initially in a horizontal and then in a vertical fashion, starting from the outside towards the centre, with swabs moistened with the appropriate solvent. The head of the swabs was placed into a 10$\mathrm{ml}$ volumetric flask containing $5 \mathrm{ml}$ of the solvent (in which the swab was soaked). Then $5 \mathrm{ml}$ of water was added to each volumetric flask. These volumetric flasks were capped and sonicated for $15 \mathrm{~min}$.

The absorbance of the solution was measured with UV-Vis spectrophotometer at $255 \mathrm{~nm}$. The \% recovery with spiked stainless steel plates was found between $88.75-98.12 \%$ which is well within the acceptance criteria with \%RSD value well in limit i.e. less than $2 \%$. Hence indicates method has good accuracy for determining aripiprazole (table 5).

Table 3: Linearity data for aripiprazole

\begin{tabular}{llll}
\hline Drug conc. $(\boldsymbol{\mu g} / \mathbf{m l})$ & mean $\mathbf{S D} \mathbf{( n = 6 )}$ & Drug recovered $(\boldsymbol{\mu g})$ & \% recovery \\
\hline 1 & $0.032 \pm 0.002$ & 0.996 & 99.68 \\
5 & $0.160 \pm 0.001$ & 4.986 & 99.93 \\
10 & $0.320 \pm 0.004$ & 10 & 90 \\
15 & $0.48 \pm 0.002$ & 14.98 & 100 \\
20 & $0.640 \pm 0.003$ & 20 & 99.65 \\
25 & $0.797 \pm 0.016$ & 24.91 & 99.98 \\
30 & $0.960 \pm 0.001$ & 29.99 & 99.89 \\
Mean & & & 0.174 \\
Standard Deviation & & & 0.174 \\
\% Relative Standard Deviation & & & \\
\hline
\end{tabular}

$\mathrm{n}=6$ each measurement was repeated in sextet, Data is expressed in mean $\pm \mathrm{SD}$.

Table 4: Recovery study for aripiprazol

\begin{tabular}{llccccc}
\hline Amt of sample $(\boldsymbol{\mu g} / \mathbf{m l})$ & Amt of std. drug added $(\boldsymbol{\mu g} / \mathbf{m l})$ & $\begin{array}{l}\text { Mean } \\
(\mathbf{n}=3)\end{array}$ & SD & \% RSD & Drug recovered ( $\boldsymbol{\mu g})$ & \% Recovery \\
\hline 10 & & 0.549 & 0.0005 & 0.105 & 17.13 & 95.20 \\
10 & 10 & 0.629 & 0.0006 & 0.110 & 19.65 & 98.29 \\
10 & 12 & 0.696 & 0.001 & 0.240 & 21.74 & 98.82 \\
Mean & & & & & & 97.44 \\
Standard Deviation & & & & & & 1.952 \\
\% Relative Standard Deviation & & & & 2 \\
\hline
\end{tabular}

Each measurement was repeated three times independently, Data is expressed in mean $\pm S D$. 
Table 5: Result obtained for the recovery of aripiprazole form spiked 180-grit stainless steel plate samples

\begin{tabular}{|c|c|c|c|}
\hline Drug spiked ( $\mu g)$ & Absorbance $(n=5)$ & Drug recovered $(\mu \mathrm{g})$ & \% Recovered \\
\hline \multirow[t]{5}{*}{1} & 0.032 & 0.981 & 98.12 \\
\hline & 0.031 & 0.95 & 95 \\
\hline & 0.029 & 0.887 & 88.75 \\
\hline & 0.03 & 0.918 & 91.87 \\
\hline & 0.032 & 0.981 & 98.12 \\
\hline \multirow[t]{5}{*}{5} & 0.155 & 4.825 & 96.5 \\
\hline & 0.153 & 4.762 & 95.25 \\
\hline & 0.154 & 4.793 & 95.87 \\
\hline & 0.152 & 4.731 & 94.62 \\
\hline & 0.156 & 4.856 & 97.12 \\
\hline \multirow[t]{5}{*}{10} & 0.305 & 9.512 & 95.12 \\
\hline & 0.309 & 9.637 & 96.37 \\
\hline & 0.307 & 9.575 & 95.75 \\
\hline & 0.311 & 9.7 & 97 \\
\hline & 0.31 & 9.66 & 96.68 \\
\hline \multirow[t]{5}{*}{15} & 0.461 & 14.38 & 95.91 \\
\hline & 0.464 & 14.48 & 96.54 \\
\hline & 0.463 & 14.45 & 96.33 \\
\hline & 0.465 & 14.51 & 96.75 \\
\hline & 0.466 & 14.54 & 96.95 \\
\hline \multirow[t]{5}{*}{20} & 0.618 & 19.29 & 96.46 \\
\hline & 0.615 & 19.2 & 96 \\
\hline & 0.617 & 19.26 & 96.31 \\
\hline & 0.619 & 19.32 & 96.62 \\
\hline & 0.62 & 19.35 & 96.78 \\
\hline Mean & & & 95.87 \\
\hline Standard Deviation & & & 1.924 \\
\hline$\%$ Relative Standard Deviation & & & 2 \\
\hline
\end{tabular}

Each measurement was repeated five times. $(n=5)$

\section{Precision}

Precision was investigated by analyzing the different concentration of aripiprazole $(20 \mu \mathrm{g} / \mathrm{ml})$ in independent replicates on the same day (intra-day) and on consecutive days (inter-day).

\section{Repeatability}

The intra-day and inter-day precisions of the proposed method was determined by performing swabbing which involved spiking aripiprazole on stainless steel surface, recovering the aripiprazole with swabs and desorbing the swabs into extraction solution diluent as described earlier in accuracy study and analyzing corresponding responses on the same day and on different days over a period of one week for different concentration of standard solution of aripiprazole $(20 \mu \mathrm{g} / \mathrm{ml})$. Results were reported in table 6,7 . The results indicate that the \% RSD values were 0.09 and 0.079 for Intraday and Interday precision respectively which were within the prescribed limits of ICH guidelines indicate good precision.

Table 6: Repeatability analysis of aripiprazole (Intraday precision)

\begin{tabular}{lllll}
\hline Drug Conc $(\boldsymbol{\mu g} / \mathbf{m l})$ & Mean absorbance $(\mathbf{n}=\mathbf{3})$ & SD & \% RSD & Drug recovered $(\boldsymbol{\mu g})$ \\
\hline 20 & 0.637 & 0.0005 & 0.090 & 19.90 \\
20 & 0.637 & 0.0015 & 0.239 & 19.89 \\
20 & 0.637 & 0.0005 & 0.090 & 19.90 \\
20 & 0.637 & 0.001 & 0.156 & 19.88 \\
20 & 0.638 & 0.001 & 0.156 & 19.91 \\
20 & 0.638 & 0.0005 & 0.090 & 19.93 \\
Mean & & & & 99.48 \\
Standard Deviation & & & & 99.54 \\
\% Relative Standard Deviation & & & & \\
\hline
\end{tabular}

Each measurement was repeated three times. $(n=3)$, Data is expressed in mean $\pm S D$.

Table 7: Repeatability analysis of aripiprazole (Interday precision)

\begin{tabular}{|c|c|c|c|c|c|}
\hline Drug conc. $(\mu \mathrm{g} / \mathrm{ml})$ & Mean absorbance $(n=3)$ & SD & \% RSD & Drug recovered $(\mu \mathrm{g})$ & \% Recovery \\
\hline 20 & 0.640 & 0.002 & 0.331 & 19.99 & 99.95 \\
\hline 20 & 0.639 & 0.0007 & 0.110 & 19.97 & 99.85 \\
\hline 20 & 0.639 & 0.0007 & 0.110 & 19.95 & 99.75 \\
\hline 20 & 0.64 & 0.0014 & 0.220 & 19.98 & 99.90 \\
\hline 20 & 0.639 & 0.0014 & 0.221 & 19.97 & 99.85 \\
\hline 20 & 0.640 & 0.0028 & 0.441 & 19.99 & 99.95 \\
\hline Mean & & & & & 99.880 \\
\hline Standard Deviation & & & & & 0.078 \\
\hline \% Relative Standard Deviation & & & & & 0.079 \\
\hline
\end{tabular}

Each measurement was repeated three times. $(n=3)$, Data is expressed in mean \pm SD. 


\section{Robustness and ruggedness}

In robustness, the drug content was analyzed under the experimental variables like a slight change in the temperature $\left(25^{\circ} \mathrm{C}\right.$, $18^{\circ} \mathrm{C}$ ). In ruggedness analyst to analyst, variation was considered. As the \% RSD values was found to less than $2 \%$, so method proves its robustness and ruggedness (table 8-10). This gives the confidence that API residues are stable and the residues concentration do not change in swab solutions during cleaning validation.

\section{LOD and LOQ}

The sensitivity of the method for estimation was determined in terms of the limit of detection (LOD) and limit of quantitation (LOQ). The LOD value of LOD was found to be $0.43 \mu \mathrm{g} / \mathrm{ml}$ and LOQ was found to be $1.32 \mu \mathrm{g} / \mathrm{ml}$ (table 11 ).
Optimization and validation of cleaning procedure for aripiprazole tablets on compression machine

Cleaning procedure validation was done to check the effectiveness of cleaning procedure.

\section{Chemical acceptance criteria}

ARL (acceptable residual limit) used to calculate chemical acceptance criteria

$$
\begin{aligned}
\text { Chemical acceptance criteria } & =\frac{(A R L x \text { recovery from SS plate surface })}{100} \\
& =\frac{(24.2 \times 95.8)}{100}
\end{aligned}
$$

$=23.18 \mu \mathrm{g} / \mathrm{cm}^{2}$

Table 8: Room temperature $\left(25^{\circ} \mathrm{C}\right)$ variation study for aripiprazole

\begin{tabular}{lllll}
\hline Drug conc. $(\boldsymbol{\mu g} / \mathbf{m l})$ & Mean absorbance $(\mathbf{n = 3})$ & SD & \% RSD & Drug recovered $(\boldsymbol{\mu g})$ \\
\hline 20 & 0.638 & 0.002 & 0.313 & 19.91 \\
20 & 0.635 & 0.002 & 0.314 & 19.83 \\
20 & 0.635 & 0.002 & 0.314 & 19.84 \\
20 & 0.641 & 0.002 & 0.312 & 20.02 \\
20 & 0.641 & 0.001 & 0.156 & 20.01 \\
20 & 0.640 & 0.002 & 0.312 & 19.99 \\
Mean & & & & 99.17 \\
Standard Deviation & & & & 99.22 \\
\% Relative Standard Deviation & & & & 0.418 \\
\hline
\end{tabular}

Each measurement was repeated three times independently. $(n=3)$, Data is expressed in mean \pm SD.

Table 9: $18{ }^{\circ} \mathrm{C}$ temperature variation study for aripiprazole

\begin{tabular}{lllll}
\hline Drug conc. $(\boldsymbol{\mu g} / \mathbf{m l})$ & Mean absorbance $(\mathbf{n}=\mathbf{3})$ & SD & \% RSD & Drug recovered $(\boldsymbol{\mu g})$ \\
\hline 20 & 0.633 & 0.001 & 0.157 & 19.77 \\
20 & 0.632 & 0.001 & 0.158 & 19.75 \\
20 & 0.633 & 0.001 & 0.157 & 19.76 \\
20 & 0.634 & 0.001 & 0.157 & 19.79 \\
20 & 0.631 & 0.001 & 0.158 & 19.72 \\
20 & 0.632 & 0.002 & 0.316 & 19.74 \\
Mean & & & & 98.76 \\
Standard Deviation & & & & 98.86 \\
\% Relative Standard Deviation & & & & \\
\hline
\end{tabular}

Each measurement was repeated three times independently. $(n=3)$, Data is expressed in mean $\pm S D$.

Table 10: Analyst to analyst variation study for aripiprazole

\begin{tabular}{lllll}
\hline Drug Conc. $(\boldsymbol{\mu g} / \mathbf{m l})$ & Mean absorbance $(\mathbf{n}=3)$ & SD & \% RSD & Drug recovered $(\boldsymbol{\mu g})$ \\
\hline 20 & 0.636 & 0.0035 & 0.555 & 19.87 \\
20 & 0.636 & 0.0007 & 0.111 & 19.87 \\
20 & 0.634 & 0.0007 & 0.111 & 19.80 \\
20 & 0.632 & 0.0007 & 0.111 & 19.74 \\
20 & 0.637 & 0.0007 & 0.110 & 19.90 \\
20 & 0.639 & 0.0014 & 0.221 & 19.95 \\
Mean & & & & 99.35 \\
Standard Deviation & & & & 99.73 \\
\% Relative Standard Deviation & & & & \\
\hline
\end{tabular}

Each measurement was repeated three times independently. $(n=3)$, Data is expressed in mean $\pm S D$.

Table 11: Regression analysis data and summary of validation parameters for proposed method

\begin{tabular}{ll}
\hline Parameters & Aripiprazole \\
\hline Linearity & $1-30(\mu \mathrm{g} / \mathrm{ml})$ \\
Regression equation & Y=0.032x+0.0006 \\
Slope & 0.032 \\
Intercept & 0.0006 \\
Correlation coefficient & 1 \\
LOD (limit of detection) $(\mu \mathrm{g} / \mathrm{ml})$ & 0.43 \\
LOQ (limit of quantitation) $(\mu \mathrm{g} / \mathrm{ml})$ & 1.32 \\
Precision (\% RSD) & 0.079 \\
Interday (n=6) & 0.090 \\
Intraday (n=6) & \\
\hline
\end{tabular}




\section{Optimization of cleaning procedure}

Samples were analyzed and compared with respect to the predetermined acceptance criteria.

\section{Validation of cleaning procedure}

For validation of cleaning procedure, the three consecutive batches of aripiprazole tablets $10 \mathrm{mg}$ were formulated and evaluated (according to each cleaning level condition) by the developed analytical method. The level of drug residue obtained from visual inspection and chemical inspection was evaluated against the ARL level. The level of drug residue obtained after final washing (of three batches) was less than the precalculated ARL value hence, it was concluded that the established procedure is responsible to achieve the expected cleanliness. The concentration of drug was found to be highest at turret $(5.166 \mu \mathrm{g} / \mathrm{swab})$ but within the ARL value i.e., $24.2 \mu \mathrm{g} / \mathrm{swab}$ (table 14, 15; fig. 4).

Table 12: Chemical inspection results of various steps and time of cleaning on turret

\begin{tabular}{llll}
\hline & & Active drug content $(\boldsymbol{\mu g} / \mathbf{m l})$ \\
\hline $\begin{array}{l}\text { Sampling } \\
\text { location }\end{array}$ & $\begin{array}{l}\text { Initial after tablet } \\
\text { production }\end{array}$ & $\begin{array}{l}\text { After wiped with } \\
\text { dry cloth }\end{array}$ & $\begin{array}{l}\text { After wiped with clean cloth wetted } \\
\text { with purified water }\end{array}$ \\
\hline TCM-04 & 44.43 & 14.28 & 12.09 \\
& 45.68 & 14.90 & 13.81 \\
& 45.218 & 14.43 & 14.12 \\
Avg. $(\mathrm{n}=3)$ & 45.11 & 14.54 & 13.34 \\
\hline
\end{tabular}

TCM-04= turret; IPA=isopropyl alcohol, each measurement was repeated three time independently. $(n=3)$

Table 13: Chemical inspection results of various steps and time of cleaning on different parts of tablet compression machine

\begin{tabular}{|c|c|c|c|c|c|c|}
\hline \multirow{3}{*}{$\begin{array}{l}\text { Sampling } \\
\text { location }\end{array}$} & \multicolumn{6}{|c|}{ Active drug content $(\mu \mathrm{g} / \mathrm{ml})$} \\
\hline & \multirow[t]{2}{*}{$\begin{array}{l}\text { Initial after tablet } \\
\text { production }\end{array}$} & \multirow[t]{2}{*}{ After wiped with dry cloth } & \multicolumn{3}{|c|}{$\begin{array}{l}\text { After rinse with potable } \\
\text { water }\end{array}$} & \multirow[t]{2}{*}{$\begin{array}{l}\text { After rinse with purified water } \\
\text { for } 3 \mathrm{~min}\end{array}$} \\
\hline & & & $2 \mathrm{~min}$ & $4 \mathrm{~min}$ & $6 \mathrm{~min}$ & \\
\hline & 22.56 & 11.15 & 6 & 5.062 & 4.593 & 4.281 \\
\hline & 23.34 & 13.18 & 6.312 & 7.25 & 4.281 & 2.406 \\
\hline & 23.81 & 12.87 & 6.312 & 5.062 & 3.968 & 2.562 \\
\hline $\begin{array}{l}\text { Average } \\
(n=3)\end{array}$ & 23.23 & 12.40 & 6.208 & 5.791 & 4.280 & 3.083 \\
\hline \multirow[t]{3}{*}{ TCM-02 } & 43.65 & 10.06 & 6.312 & 6 & 3.187 & 2.25 \\
\hline & 44.59 & 10.84 & 6.156 & 5.531 & 3.5 & 2.875 \\
\hline & 44.75 & 11.78 & 7.093 & 4.75 & 4.437 & 3.5 \\
\hline $\begin{array}{l}\text { Average } \\
(n=3)\end{array}$ & 44.33 & 10.89 & 6.520 & 5.427 & 3.708 & 2.875 \\
\hline \multirow[t]{3}{*}{ TCM-03 } & 16.15 & 9.593 & 8.031 & 3.968 & 3.5 & 2.406 \\
\hline & 17.25 & 11 & 9.125 & 3.968 & 3.812 & 1 \\
\hline & 16.62 & 11.93 & 9.75 & 3.187 & 4.437 & 1.156 \\
\hline $\begin{array}{l}\text { Average } \\
(n=3)\end{array}$ & 16.67 & 10.84 & 8.968 & 3.707 & 3.916 & 1.520 \\
\hline \multirow[t]{3}{*}{ ТСM-05 } & 33.96 & 21 & 5.531 & 5.218 & 3.656 & 2.562 \\
\hline & 34.28 & 22.40 & 6.468 & 4.437 & 3.343 & 3.031 \\
\hline & 34.43 & 21.62 & 6 & 4.281 & 3.968 & 2.875 \\
\hline $\begin{array}{l}\text { Average } \\
(n=3)\end{array}$ & 34.22 & 21.67 & 5.999 & 4.645 & 3.655 & 2.822 \\
\hline
\end{tabular}

TCM-01= hopper top cylinder; TCM-02=hopper middle cone; TCM-03= hopper discharge chute; TCM-04= turret; TCM-05=chute, each measurement was repeated three time independently. $(n=3)$

Table 14: Visual inspection results of tablet compression machine after cleaning

\begin{tabular}{|c|c|c|c|c|}
\hline \multirow[t]{2}{*}{ S. No. } & \multirow[t]{2}{*}{ Areas for visual observation } & \multicolumn{3}{|c|}{ Visually clean: Yes/No $(n=3)$} \\
\hline & & Batch-1 & Batch-2 & Batch-3 \\
\hline 1. & Doors & Yes & Yes & Yes \\
\hline 2. & Hopper & Yes & Yes & Yes \\
\hline 3. & Turret & Yes & Yes & Yes \\
\hline 4. & Discharge chute & Yes & Yes & Yes \\
\hline
\end{tabular}

Each measurement was repeated three time independently. $(\mathrm{n}=3)$

Table 15: Chemical inspection results of tablet compression machine after cleaning

\begin{tabular}{|c|c|c|c|c|}
\hline \multirow[t]{2}{*}{ S. No. } & \multirow[t]{2}{*}{ Sampling location } & \multicolumn{3}{|c|}{ Active drug content $(\mu \mathrm{g} / \mathrm{swab})(\mathrm{n}=3)$} \\
\hline & & Batch-1 & Batch-2 & Batch-3 \\
\hline 1. & TCM-01 & 4.281 & 2.406 & 2.562 \\
\hline 2. & TCM-02 & 2.25 & 2.875 & 3.5 \\
\hline 3. & TCM-03 & 2.406 & 1 & 1.156 \\
\hline 4. & TCM-04 & 4.75 & 5.687 & 5.062 \\
\hline 5. & TCM-05 & 2.562 & 3.031 & 2.875 \\
\hline
\end{tabular}

TCM-01= hopper top cylinder; TCM-02=hopper middle cone; TCM-03= hopper discharge chute; TCM-04= turret; TCM-05=chute, each measurement was repeated three times independently. $(n=3)$ 


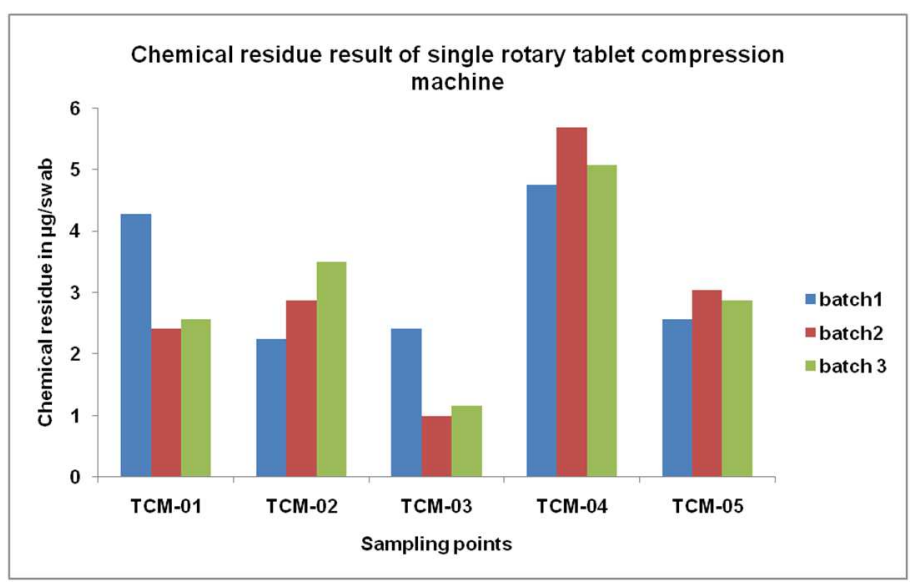

Fig. 5: Comparation of chemical residue content of three batches at various locations of tablet compression machine after cleaning, TCM01= hopper top cylinder; TCM-02=hopper middle cone; TCM-03= hopper discharge chute; TCM-04= turret; TCM-05=chute

Hence the developed cleaning method removes even traces of residue of drug present on the instrument. Analytical method developed was found to be linear, precise, accurate and sensitive to detect even small quantity of drug residue in view of cleaning validation. Cleaning standard operating procedure provides sufficient removal of the residues from equipment surfaces and totally excludes the risk of cross contamination.

\section{CONCLUSION}

Cleaning procedure was optimized by changing the variables and determination of drug residues on different parts of tablet machine in different steps of cleaning. Cleaning validation was executed on tablet compression machine. Three consecutive batches of aripiprazole tablets were formulated for cleaning validation study. The chemical residue of the drug at various parts of the equipment surfaces was found within the predefined acceptance criteria.

Swab sampling and UV method were developed and validated for the quantitative estimation of aripiprazole residues on stainless steel surfaces of plant equipment after manufacturing of aripiprazole $10 \mathrm{mg}$ uncoated tablets to demonstrate cleaning validation. Methods with appropriate swab wipe procedure were found to be selective, accurate, precise and linear. No interference from swab solution was observed and samples were stable during analysis for residual estimation. Hence, the results obtained confirm that the cleaning procedures used are able to remove residues from equipment surfaces and well below the calculated limit of contamination.

The swab sampling and UV method can be used in other pharmaceutical quality control laboratories to apply successfully in cleaning validation for quantitative estimation of aripiprazole residues after manufacturing of aripiprazole uncoated tablets.

\section{CONTRIBUTION}

Ms. Sukhpreet Kaur (Research Scholar) performed practical work. Ms. Indu Bala has supervised the practical work and compiled it. Dr. Anjoo Kamboj has helped in the compilation of results and prepared the manuscript. Dr. Upendra K Jain has worked as an overall supervisor.

\section{CONFLICT OF INTERESTS}

\section{Declared none}

\section{REFERENCES}

1. Agalloco J. Points to consider in the validation of equipment cleaning procedures. J Pharm Sci Tech 1992;46:168-75.

2. Venugopal S. Designing of cleaning validation program for active pharmaceutical ingredients. World J Pharm Res 2014;3:3819-44.
3. FDA. Guide to inspections of validation of cleaning processes; 1993.

4. Leblan C, Destin A. Establishing scientifically justified acceptance criteria for cleaning validation of finished drug products. AAPS PharmSciTech 1998;22:136-48.

5. Appleby C. Principal of cleaning validation. Global Quality Operation; 2010. p. 1-24.

6. Lodhi B, Padamwari P, Patel A. Cleaning validation for the pharmaceuticals, biopharmaceuticals, cosmetic and nutraceuticals industries. J Innovations Pharm Biol Sci 2014;1:27-38.

7. Grobin AW. Cleaning verification/validation of pharmaceutical manufacturing equipment from a laboratory perspective. Southern California Pharmaceutical Discussion Group; 2013.

8. Mollah AH. Cleaning validation of biopharmaceutical manufacturing at Genentech, Inc. Part 2. Biopharm; 2008. p. 21.

9. Pawar HA, Banerjee ND, Pawar S, Pawar P. Current perspectives on cleaning validation in the pharmaceutical industry: a scientific and risk-based approach. Int J Pharm Phytopharm Res 2011;1:8-16.

10. Kumar S, Bharat P. A review on the concept of cleaning validation in pharmaceutical industry. Int Res J Pharm 2012;3:17-9.

11. Waghmare PV, Chinchole AS, Poul BN, Bhusnure OG. A brief review on cleaning validation and its significance in pharmaceutical industry. Int J Pharm Sci 2013;4:165-92.

12. Ghosh A, Dey S. Overview of cleaning validation in pharmaceutical industry. Int J Pharm Quality Ass 2010;2:26-30.

13. APIC. Cleaning validation in active pharmaceutical ingredient manufacturing plant. A guide to Cleaning Validation in API Plants; 1999.

14. Asgharian R, Hamedani FM, Heydari A. Step by step how to do cleaning validation. Int J Pharm Sci 2014;5:3345-66.

15. Ravichandran V, Shalini S, Sundram KM, Rajak H. Validation of analytical methods-strategies and importance. Int J Pharm Pharm Sci 2010;2:18-22.

16. Daksh S, Goyal A, Pandiya CK. Validation of analytical methodsstrategies and significance. Int J Res Dev Pharm Sci 2015;4:1489-7.

17. Lavanya G, Sunil M, Eswarudu MM, Eswaraiah MC, Harisudha K, Naga B. Analytical method validation: an updated review. Int J Pharm Sci Res 2013;4:1280-6.

18. ICH. Harmonised tripartite guideline, validation of analytical procedures, text and methodology Q2 (R1); 2005.

19. Geetha G, Karanam NGR, Kumar BV, Raja MG. Analytical method validation: an updated review. Int J Adv Pharm Biol Chem 2012;1:64-71.

20. Yanamadala G, Gupta VR, Kumar PP, Lavanya N. Cleaning validation for residual determination of valganciclovir hydrochloride on stainless steel surface of pharmaceutical manufacturing equipment using HPLC-Dad method. Int J Res Pharm Chem 2013;3:782-9. 
21. Patel S, Kamath K, Shabaraya R. Evaluation of cleaning method validation techniques of ciprofloxacin. Int J Pharm Chem Sci 2012;1:1118-27.

22. Sandeep K, Induri MSR, Sudhakar M. Validated spectrophotometric quantification of aripiprazole in pharmaceutical formulations by using the multivariate technique. Adv Pharm Bull 2013;3:469-72.

23. Kathiresan K, Prathyushal Y, Moorthil C, Sha NAD, Krishnan K, Manavalan R. Cleaning validation of ibuprofen and methocarbamol tablets. Int J Drug Dev Res 2011;3:300-6.

24. Dhoka MV, Vaidya PD, Pande AV, Arora AA. Development and validation of analytical method for estimation of cefixime in swab samples. Int J Chem Tech Res 2010; 2:1918-23.

25. Rubashvili I, Karukhnishvili N, Loria K, Dvali N. Cleaning validation for estimation of active ingredients' residues of vicazid uncoated tablets (pyrantel $100 \mathrm{mg} /$ mebendazole 150 $\mathrm{mg}$ ) on surfaces of pharmaceutical manufacturing equipment using swab sampling and HPLC method. Int J Pharmacol Pharm Sci 2015;7:158-69.

26. Ivaturi KV, Yu SK, Mulla U, Reddy M. Method development and validation of cleaning procedure for fenbendazole residual determination in manufacturing. Asian J Plant Res 2016;9:316-29.

27. www.tabletpress.co.in/tabletpress_mini_singlerotary.html. [Last accessed on 20 May 2016]

28. Theivarasu C, Ghosh S, Indumathi T. UV spectrophotometric determination of carvedilol in pharmaceutical formulations. Asian J Pharm Clin Res 2010;3:64-8.

29. https://en.wikipedia.org/wiki/Aripiprazole. [Last accessed on 20 May 2016]

\section{How to cite this article}

- Sukhpreet Kaur, Indu Bala, Anjoo Kamboj, Upendra K Jain. Development and validation of analytical method for estimation of aripiprazole in swab samples on pharmaceutical manufacturing equipment surfaces for cleaning validation. Int J Pharm Pharm Sci 2017;9(5):141-151. 